\title{
CYP2A13, CYP2A6, and the Risk of Lung Adenocarcinoma in a Japanese Population
}

\author{
Chikako Kiyohara, ${ }^{*, a}$ Koichi Takayama, ${ }^{b}$ and Yoichi Nakanishi ${ }^{b}$ \\ ${ }^{a}$ Department of Preventive Medicine and ${ }^{b}$ Research Institute for Diseases of the Chest, Graduate School of Medical Sciences, Kyushu \\ University, 3-1-1 Maidashi, Higashi-ku, Fukuoka 812-8582, Japan
}

(Received June 13, 2005; Accepted August 25, 2005)

\begin{abstract}
Both cytochrome P450 (CYP) 2A6 and CYP2A13 are involved in the metabolic activation of tobacco-specific $N$-nitrosamines (TSNAs). Some kinds of TSNAs induce lung adenocarcinoma in laboratory animals. Thus, polymorphisms of $C Y P 2 A 6$ and $C Y P 2 A 13$ genes may be important as genetic factors of lung cancer, particularly lung adenocarcinoma. We genotyped 179 patients with lung cancer and 183 controls for $C Y P 2 A 6$ gene deletion-type and CYP2A13 C3375T polymorphisms by polymerase chain reaction-based techniques on DNA prepared from peripheral blood. In addition, a questionnaire was used to collect demographic, lifestyle and other information from each subject. Unconditional logistic regression was used to compute the odds ratios (ORs) and their 95\% confidence intervals (95\% CIs), with adjustments for several covariates found to be associated with risk. Compared with one or more copies of the T allele, the $C Y P 2 A 13 C C$ genotype was associated with a substantially increased risk for lung adenocarcinoma $(\mathrm{OR}=2.41,95 \% \mathrm{CI}=1.03-6.28)$. Smokers with the $C Y P 2 A 13 C C$ genotype showed significantly higher risk $(\mathrm{OR}=4.88,95 \% \mathrm{CI}=1.35-26.53)$ compared to non-smokers with possession at least one copy of the $C Y P 2 A 13 T$ allele. Although our results indicate that the CYP2A13 gene may play a role in the development of lung adenocarcinoma, the risk for those individuals with single at-risk genotype of $C Y P 2 A 13 \mathrm{C} 3375 \mathrm{~T}$ polymorphism may not be so large. In future studies, analyses based on haplotypes are recommended to confirm the role of $C Y P 2 A 13$ gene in the development of lung adenocarcinoma.
\end{abstract}

Key words — lung adenocarcinoma, $C Y P 2 A 6, C Y P 2 A 13$, tobacco specific $N$-nitrosamine

\section{INTRODUCTION}

Lung cancer remains one of the major causes of mortality in many developed countries. ${ }^{1)}$ Although cigarette smoking is the main cause of lung cancer, not all smokers develop the disease, and only a fraction of lifelong non-smokers will die from it. Genetic host factors have recently been implicated to account for some of the observed differences in susceptibility. In this respect, drug metabolizing enzymes are the most studied biotransforming enzymes. The polymorphic expression of these enzymes has been associated with individual cancer susceptibility. ${ }^{2-4)}$

The CYP2A subfamily has been shown to exhibit high activity toward tobacco-specific $N$-nitro-

\footnotetext{
*To whom correspondence should be addressed: Department of Preventive Medicine, Graduate School of Medical Sciences, Kyushu University, Maidashi 3-1-1, Higashi-ku, Fukuoka 8128582, Japan. Tel.: +81-92-642-6113; Fax: +81-92-642-6115; Email: chikako@phealth.med.kyushu-u.ac.jp
}

samines (TSNAs) such as 4-(methylnitrosamino)1-(3-pyridyl)-1-butanone (NNK) and $N^{\prime}$ nitrosonornicotine $(\mathrm{NNN}){ }^{5,6)} \mathrm{CYP} 2 \mathrm{~A} 6$ is also involved in the metabolism of nicotine and the persistence of tobacco dependence. ${ }^{7)}$ Three members of the $C Y P 2 A$ gene subfamily, $C Y P 2 A 6, C Y P 2 A 7$, and $C Y P 2 A 13$, have been identified in humans. ${ }^{8}$ The CYP2A6 gene has been mapped to the long arm of chromosome 19 , in a $350 \mathrm{~kb}$ region containing both $C Y P 2 A 7$ and $C Y P 2 A 13$. Several variants of the $C Y P 2 A 6$ gene have been identified to date. Among those, $C Y P 2 A 6 * 2$ (Ile160His, T479A), CYP2A6*4 (the deletion alleles; 4A, 4B and 4D), and $C Y P 2 A 6 * 5$ (Gly479Val, G1436T) may abolish catalytic activity. ${ }^{9-11)}$ A decreased capacity to activate carcinogens may be associated with a decreased risk of developing lung cancer. London et al. showed that a decreased risk of lung cancer [odds ratio $(\mathrm{OR})=0.5$, $95 \%$ confidence intervals $(\mathrm{CI})=0.1-2.1]$ was observed among individuals with both $C Y P 2 A \sigma^{*} 2$ and $C Y P 2 A 6 * 3$ alleles. ${ }^{12)}$ The $C Y P 2 A 6 * 4$ allele has been associated with a decreased risk of lung cancer 
Table 1. Selected Characteristics of Lung Cancer Patients and Healthy Controls

\begin{tabular}{|c|c|c|c|c|c|c|}
\hline & \multirow[b]{2}{*}{$\mathrm{n}$} & \multirow[b]{2}{*}{$\begin{array}{c}\text { Mean age } \\
\text { (range) }\end{array}$} & \multirow{2}{*}{$\begin{array}{l}\text { Brinkman } \\
\text { index } \\
\text { (median) }\end{array}$} & \multirow{2}{*}{$\begin{array}{c}\text { Prevalence } \\
\text { of smokers } \\
(\%)\end{array}$} & \multicolumn{2}{|c|}{ Frequency of genotypes, n (\%) } \\
\hline & & & & & $\begin{array}{c}C Y P 2 A 6 \text { deletion-type } \\
\text { polymorphism } \\
* 1 / * 4+* 4 / * 4\end{array}$ & $\begin{array}{c}C Y P 2 A 13 \mathrm{C} 3375 \mathrm{~T} \\
\text { polymorphism } \\
C T+T T\end{array}$ \\
\hline Lung cancer patients & 179 & $64.3(35-86)$ & 700 & 69.8 & $44(24.6)$ & $24(13.5)$ \\
\hline Adenocarcinoma & 88 & $61.5(35-84)$ & 65 & 50 & $19(21.5)$ & $11(12.5)$ \\
\hline Squamous cell carcinoma & 55 & $67.8(36-80)$ & 1000 & 85.5 & $14(25.5)$ & $7 \quad(2.1)$ \\
\hline Small cell carcinoma & 27 & $66.4(52-78)$ & 1000 & 100 & $6(22.2)$ & $5(18.5)$ \\
\hline Large cell carcinoma & 9 & $63.3(52-86)$ & 900 & 77.8 & $3(33.3)$ & $1(11.1)$ \\
\hline Control individuals & 183 & $57.7(32-86)$ & 500 & 42.1 & $34(18.6)$ & $32(17.5)$ \\
\hline
\end{tabular}

among Japanese populations. ${ }^{13-16)}$ In contrast to those findings among Japanese, Chinese individuals with at least one $C Y P 2 A 6^{*} 4$ deletion allele were at a 2fold $(95 \% \mathrm{CI}=1.2-3.2)$ increased risk of developing lung cancer compared with those without any CYP2A6*4 allele. ${ }^{17)}$

CYP2A13 has been found predominantly in the respiratory tract. ${ }^{18)}$ The catalytic activity of CYP2A13 toward NNK is more efficient than that of CYP2A6. ${ }^{18)}$ Zhang et al. ${ }^{19,20)}$ and Fujieda et al. ${ }^{21)}$ have analyzed structural variations in the CYP2A13 gene. A C to $\mathrm{T}$ transition in exon 5 of the CYP2A13 (CYP2A13*7 allele, C3375T, Arg257Cys) has been shown to lead to a significant reduction in enzymatic activity (half the activity of the wild-type enzyme). ${ }^{19)}$ This missense mutation occurs with varying frequency, ranging from $2 \%$ in a white population to $14 \%$ in a black population. ${ }^{19)}$ Wang et al. reported that that the variant $C Y P 2 A 13$ allele is associated with a reduced risk of lung adenocarcinoma in a Chinese population. ${ }^{22)}$ Another nonsense mutation polymorphism, C301T (CYP2A13*7 allele, Arg101Stop), which was detected in a Chinese population, is likely to be functionally important since it entails a severely truncated protein lacking enzymatic activity. ${ }^{20)}$ Zhang et al. reported that this variant allele also exhibits a protective effect against procarcinogens in the respiratory tract. ${ }^{20)}$ This CYP2A13 C $301 \mathrm{~T}$ polymorphism has been associated with the risk of small cell lung cancer. ${ }^{23)}$

To more fully evaluate the relationship between lung adenocarcinoma and smoking, we conducted a case-control study of lung cancer in a Japanese population with special reference to the interaction between smoking and either the CYP2A6 deletion-type or CYP2A13 C3375T polymorphism.

\section{MATERIALS AND METHODS}

Study Subjects and Data Collection — This case-control study involved 179 male patients with lung cancer and 183 healthy male controls who were employees of the Fukuoka Prefectural Government. Details are shown elsewhere. ${ }^{24)}$ Subjects with histologically confirmed primary lung cancer were recruited from September 1996 to September 1998 at the Kyushu University Hospital (Research Institute for Diseases of the Chest, Kyushu University). All subjects were unrelated ethnic Japanese. Information on smoking and drinking habits, family history of cancer, possible occupational exposure and medications was gathered from both patients and controls. Table 1 summarizes characteristics with respect to age, Brinkman index (number of cigarettes smoked per day multiplied by number of years of smoking), prevalence of smokers, and distribution of CYP2A6 deletion-type and the CYP2A13 C3375T polymorphisms among lung cancer patients and healthy controls.

The study protocol was approved by our institutional review board, and all participants provided written informed consent.

Genetic Analyses — Genomic DNA was extracted from buffy coat stored at $-80^{\circ} \mathrm{C}$ using the QIAamp blood kit (QIAGEN, Inc., Santa Clarita, CA, U.S.A.) and genotyped by polymerase chain reaction based-techniques. Genotyping was conducted with blinding to case/control status. CYP2A6 genotypes were analyzed for the wild-types $\left(C Y P 2 A 6^{*} 1 A\right.$ and $\left.C Y P 2 A 6^{*} 1 B\right)$, and the deletiontype $\left(C Y P 2 A 6^{*} 4\right)$ by the method established by Ariyoshi et al. ${ }^{25)}$ The $C Y P 2 A 6^{*} 4$ allele in this study is the $C Y P 2 A \sigma^{*} 4 A$, which is equivalent to $C Y P 2 A 6^{*} 4 C,{ }^{25)}$ a major causal allele in Japanese lacking CYP2A6 activity. ${ }^{26,27)}$ Therefore, the 
Table 2. Risk of Lung Cancer Associated with $C Y P 2 A 6$ and $C Y P 2 A 13$ Genotypes by Histological Types

\begin{tabular}{lcccc}
\hline \hline Polymorphism & All cases & $\begin{array}{c}\text { Cases with } \\
\text { adenocarcinoma }\end{array}$ & $\begin{array}{c}\text { Cases with } \\
\text { squamous cell carcinoma }\end{array}$ & $\begin{array}{c}\text { Cases with other } \\
\text { cell types }\end{array}$ \\
\hline $\begin{array}{l}\text { CYP2A6 deletion-type polymorphism } \\
* 1 / * 1\end{array}$ & $0.97(0.57-1.66)$ & $0.89(0.45-1.96)$ & $0.90(0.43-1.96)$ & $0.94(0.39-2.45)$ \\
$* 1 / * 4+* 4 / * 4$ & 1.00 (reference) & 1.00 (reference) & 1.00 (reference) & 1.00 (reference) \\
\multicolumn{2}{l}{ CYP2A13 C3375T polymorphism } & & & \\
$C C$ & 1.50 (0.81-2.81) & $2.41(1.03-6.28)$ & $1.73(0.66-5.36)$ & $1.03(0.42-2.80)$ \\
$C T+T T$ & 1.00 (reference) & 1.00 (reference) & 1.00 (reference) & 1.00 (reference) \\
\hline
\end{tabular}

Other cell types include small cell carcinoma $(n=27)$ and large cell carcinoma $(n=9)$. Adjusted for age, sex, smoking status, alcohol intake and family history of lung cancer.

CYP2A6 genotypes were categorized into $* 1 / * 1$, $* 1 / * 4$, and $* 4 / * 4$ (the deletion type). The genotypes of CYP2A13 C3375T polymorphism were analyzed by the method by Zhang et al. ${ }^{19)}$ The wild-type $\mathrm{C}$ allele had a Hha I restriction site that resulted in two bands ( 217 and $58 \mathrm{bp}$ ) and the $\mathrm{T}$ allele lacked the restriction site. For quality control, both assays were repeated on a random $5 \%$ of all samples, and the replicates were $100 \%$ concordant.

Statistical Analysis — We used $\chi^{2}$ statistics for homogeneity to test for case-control differences in the distribution of genotypes or other parameters under study. Unconditional logistic regression was used to compute the ORs and their 95\% CIs, with adjustments for several covariates found to be associated with risk (age, sex, smoking status, alcohol intake, and family history of lung cancer). Subjects were considered current-smokers who had smoked before either the date of diagnosis for lung cancer or the date of filling out the questionnaires. Nonsmokers were defined as those who had smoked fewer than 365 cigarettes in their lifetime. Since very few subjects were ex-smokers, they were included in the current-smokers category. To test for statistical interactions between genotypes and smoking status, we entered interaction terms reflecting the product of genotype and smoking status into the logistic models.

All statistical analyses were performed using the computer program STATA Version 8 (STATA Corporation, College Station, TX, U.S.A.). All P values were two-sided, with those less than 0.05 considered statistically significant.

\section{RESULTS}

Our analysis included 179 lung cancer patients (88 with adenocarcinoma, 55 with squamous cell carcinoma, 27 with small cell carcinoma, and 9 with large cell carcinoma). The distributions of selected characteristics among subjects are summarized in Table 1. There were no significant differences between cases and controls in terms of age distribution (data not shown). As for the median of the Brinkman index, fewer cigarettes were smoked by subjects with adenocarcinoma compared to those with other cell types $(p<0.001)$. The median Brinkman index was lower in cases with adenocarcinoma than in controls, although the prevalence of smokers was similar between them. Regarding the CYP2A6 deletion-type polymorphism, the distribution of $* 1 / * 1, * 1 / * 4$, and $* 4 / * 4$ genotypes among controls was $81.4,17.5$, and $1.0 \%$, respectively. As for the CYP2A13 C3375T polymorphism, the frequency of the three genotypes $C C, C T$, and $T T$ among controls was $82.5,16.4$ and $1.1 \%$, respectively. The allelic frequencies of the CYP2A6 deletion-type or CYP2A13 C3375T polymorphism in controls were calculated to be Hardy-Weinberg linkage equilibrium: 0.902 and 0.098 for the $* 1$ and $* 4$ allele; 0.907 and 0.093 for the $C$ and $T$ allele, respectively. Distribution of the $* 4 / * 4$ and $* 1 / * 4$ genotypes combined or the $T T$ and $C T$ genotypes combined did not differ among different histological types. Genotype distributions of $C Y P 2 A 6$ and $C Y P 2 A 13$ were similar between cases and controls. Since both the $C Y P 2 A 6$ *4/*4 and CYP2A13 TT genotypes were extremely rare in our Japanese population, they were combined with the $C Y P 2 A 6 * 1 / * 4$, respectively, or $C Y P 2 A 13$ $C T$ for subsequent analysis.

Table 2 represents adjusted ORs and $95 \%$ CIs for all lung cancer and specific cell types by $C Y P 2 A 6$ 
Table 3. Risk of Lung Cancer Associated with $C Y P 2 A 6$ Genotypes by Histological Types

\begin{tabular}{llll}
\hline \hline Genotype + Smoking & All cases & $\begin{array}{c}\text { Cases with } \\
\text { adenocarcinoma }\end{array}$ & $\begin{array}{c}\text { Cases with other } \\
\text { cell types }\end{array}$ \\
\hline$* 1 / * 1+$ smoking $(+)$ & $1.76(0.85-3.66)$ & $1.02(0.43-2.46)$ & $3.24(1.23-9.50)$ \\
variant + smoking $(+)$ & $1.43(0.69-2.98)$ & $0.97(0.25-3.71)$ & $2.48(0.26-6.72)$ \\
$* l / * 1+$ smoking $(-)$ & $0.80(0.18-3.52)$ & $0.66(0.28-1.61)$ & $1.14(0.26-5.09)$ \\
variant + smoking $(-)$ & 1.00 (reference) & 1.00 (reference) & 1.00 (reference) \\
$P_{\text {interaction }}$ & 0.64 & 0.62 & 0.91 \\
\hline
\end{tabular}

Other cell types $(n=91)$ include squamous cell carcinoma $(n=55)$, small cell carcinoma $(n=27)$ and large cell carcinoma $(n=9)$. Adjusted for age, sex, alcohol intake and family history of lung cancer. Variant indicates combined genotype, which has at least one variant allele $(* 1 / * 4+* 4 / * 4)$.

Table 4. Risk of Lung Cancer Associated with $C Y P 2 A 13$ Genotypes by Histological Types

\begin{tabular}{|c|c|c|c|}
\hline Genotype + Smoking & All cases & $\begin{array}{c}\text { Cases with } \\
\text { adenocarcinoma }\end{array}$ & $\begin{array}{l}\text { Cases with other } \\
\text { cell types }\end{array}$ \\
\hline$C C+$ smoking $(+)$ & $3.45(1.55-7.97)$ & $4.88(1.35-26.53)$ & $2.38(0.49-11.63)$ \\
\hline variant + smoking $(+)$ & $2.56(0.73-8.99)$ & $4.76(0.61-38.86)$ & $0.92(0.37-2.24)$ \\
\hline$C C+$ smoking $(-)$ & $1.14(0.49-2.74)$ & $2.27(0.91-24.08)$ & $0.80(0.18-3.52)$ \\
\hline variant + smoking $(-)$ & 1.00 (reference) & 1.00 (reference) & 1.00 (reference) \\
\hline$P_{\text {interaction }}$ & 0.84 & 0.48 & 0.33 \\
\hline
\end{tabular}

or $C Y P 2 A 13$ genotype. The presence of at least one copy of the CYP2A6*4 allele was not associated with the risk of overall lung cancer or adenocarcinoma. According to histological type, the CYP2A13 CC genotype was significantly associated with an increased risk of adenocarcinoma $(\mathrm{OR}=2.41,95 \%$ $\mathrm{CI}=1.03-6.28)$ compared to one or more copies of the $T$ allele. The joint effects of CYP2A6 and CYP2A13 genotypes were assessed separately in adenocarcinoma and other cell types combined. Lung cancer risk was compared between individuals with variant allele(s) and those with no variant allele. No clear association was found in the joint effects for adenocarcinoma or other cell types combined (data not shown).

Table 3 shows the modifying effect of the CYP2A6 genotypes on the association of smoking with lung cancer risk. Smokers with the $* 1 / * 1$ genotype presented a higher risk of lung cancer (other than adenocarcinoma) than those with at least one variant allele $(\mathrm{OR}=3.24,95 \% \mathrm{CI}=1.23-9.50)$ as compared to non-smokers with at least one variant allele. The $* 1 / * 1$ genotype was not associated with an increased risk of adenocarcinoma. Smoking was associated with an increased risk of lung cancer other than adenocarcinoma $(\mathrm{OR}=11.15,95 \% \mathrm{CI}=5.37-$ 25.50) (data not shown). The interactions between genotypes and smoking were far from significant $\left(P_{\text {interaction }}=0.64,0.62\right.$ and 0.91$)$, and smoking was not strongly associated with adenocarcinoma $(\mathrm{OR}=$ $1.38,95 \% \mathrm{CI}=0.80-2.37$ ) (data not shown).

Table 4 shows the modifying effect of $C Y P 2 A 13$ genotypes on the association of smoking with lung cancer. The adjusted OR for lung cancer was significantly high in smokers with the $C C$ genotype (OR $=3.45,95 \% \mathrm{CI}=1.55-7.97)$ compared to non-smokers with the variant genotype (the $C T$ and $T T$ genotypes combined) while the corresponding value of smokers with the variant genotype was not significant $(\mathrm{OR}=2.56,95 \% \mathrm{CI}=0.73-8.99)$. A gene-environment interaction among adenocarcinoma patients was suggested, with a combination of the CYP2A13 CC genotype with smoking conferring a significantly higher risk $(\mathrm{OR}=4.88,95 \% \mathrm{CI}=1.35$ 26.53) compared to a combination of at least one copy of the CYP2A13 T allele with non-smoking. Results of the multiplicative interaction test, however, were not significant $\left(P_{\text {interaction }}=0.48\right)$. The ORs of smokers with the $C Y P 2 A 6 C C$ genotype and those with variant genotypes were almost the same. 


\section{DISCUSSION}

Principal histological types of lung cancer are squamous cell carcinoma, large cell carcinoma, small cell carcinoma and adenocarcinoma, and the former three are strongly associated with smoking. In recent decades, the frequency of adenocarcinoma has risen and that of squamous cell carcinoma has declined in a number of developed countries. ${ }^{28-33)}$ The increase in incidence of adenocarcinoma could be partly explained by an increase in filtered cigarette smoking. Filter cigarettes with low-tar and low-nicotine have replaced nonfilter cigarettes. One key characteristic of such changes over time has been an increased nitrate content of the tobacco blends from about 0.5 to $1.3 \% .^{34)}$ TSNAs are formed by the $\mathrm{N}$ nitrosation of nicotine and other minor alkaloids during tobacco processing and while smoking. ${ }^{35)}$ Since nitrate is the major precursor of nitrogen oxides, increased nitrate content leads to higher yields of NNK in the smoke. ${ }^{36)}$ To satisfy a craving for nicotine, a smoker of low-yield nicotine filtered cigarettes may tend to compensate by increasing the number and depth of puffs. Therefore, the peripheral lung, where adenocarcinoma generally arises, is exposed to higher amounts of smaller particles such as NNK. Indeed, NNK is a systemic carcinogen that has been shown to induce lung carcinoma in laboratory animals independent of the site of application, whereas the intratracheal inhalation of benzo $[a]$ pyrene and other polycyclic aromatic hydrocarbons has preferentially induced squamous cell carcinoma. ${ }^{37)}$

Adenocarcinoma is the most frequent type of lung cancer that is observed in the population among non-smokers. Passive smoking, involuntary smoking and environmental tobacco smoke (ETS) are often used synonymously to describe the involuntary exposure of non-smokers. ETS is comprised of diluted sidestream smoke from the smoldering of the cigarette between puffs and mainstream smoke exhaled by the smokers. Today ETS is judged to be a cause of lung cancer in non-smokers by IARC. ${ }^{38)}$ ETS contains over 40 known carcinogens, including polycyclic aromatic hydrocarbons, nitrosamines, and TSNAs, nitrosamines from nicotine. ${ }^{39)}$ The most abundant constituent in ETS is NNK. ${ }^{39)}$ As it is biologically plausible that TSNAs such as NNK, which is metabolized by both CYP2A6 and CYP2A13, causes adenocarcinoma in humans, low activity of both CYP2A6 and CYP2A13 may be associated with a decreased risk of lung adenocarcinoma.

In this study, we observed an allelic frequency of $9.8 \%$ for the $C Y P 2 A 6^{*} 4$ among controls. Frequency of the $C Y P 2 A 6^{*} 4$ allele in our study is onehalf of that reported by other Japanese studies (18.4$20.4 \%) .^{14,15,40)}$ Frequencies of the deletion allele among two Chinese populations were 8.6 and $8.0 \% .{ }^{17,22)}$ The reasons remains unclear for the discrepancy in the frequency of the CYP2A6*4 allele between our study and those of other Japanese as well as for the agreement between the two Chinese populations and ours. In this connection, the CYP2A6*4 alleles were found to be fairly common in Chinese and Japanese but rare in Caucasians (0.5$3.0 \%) .{ }^{41-43)}$ An allelic frequency of $9.3 \%$ for the CYP2A13 $T$ allele shown among controls in the present study is similar to that among Chinese $(9 \%){ }^{22)}$ The Chinese study ${ }^{22)}$ is the only study to investigate the effect of $C Y P 2 A 13$ polymorphism on susceptibility to lung cancer.

As lung adenocarcinoma is likely to be linked to NNK, ${ }^{37)}$ a protective effect of the variant genotypes (decreased metabolic activation activity) on cancer risk has been assumed. In the present study, we could find no significant association between the CYP2A6 deletion-type polymorphism and the risk of adenocarcinoma. Nor was such an association observed in another study ${ }^{22}$ However, the whole CYP2A6 gene deletion was associated with a significantly decreased risk of lung cancer among Japanese populations. ${ }^{13-16)}$ In the above studies, the effects of the $* 4$ allele on adenocarcinoma were less significant than those on other cell types. The lower allelic frequency of the $C Y P 2 A \sigma^{*} 4$ allele in our study compared to that in other Japanese studies may have led to conflicting results. In contrast, it has been reported that Chinese with at least one $C Y P 2 A 6 * 4$ allele were at a 2 -fold $(95 \% \mathrm{CI}=1.2-3.2)$ greater risk of lung cancer (unspecified cell types) compared with those without the $C Y P 2 A 6^{*} 4$ allele. ${ }^{17)}$ Furthermore, the authors concluded that the effect of $C Y P 2 A 6^{*} 4$ on lung cancer risk was mainly limited to squamous cell carcinoma. The relationship between the $C Y P 2 A 6$ gene and lung cancer remains questionable.

Among several genetic polymorphisms of the CYP2A13 gene, a single nucleotide polymorphism has been detected in exon 5, leading to an Arg257Cys amino acid change (C3375T). ${ }^{19)}$ Since the 257Cys allele has been shown to contribute to decreased catalytic efficiency ${ }^{19}{ }^{9}$ it might provide some protec- 
tion against TSNAs in lung cancer. However, compared with $C Y P 2 A 6$, little is known about the possible association of this polymorphism with lung cancer risk. In this study, compared with individuals with one or more copies of the $\mathrm{T}$ allele, those with the CYP2A13 CC genotype presented the strongest association with adenocarcinoma $(\mathrm{OR}=2.41$, $95 \% \mathrm{CI}=1.03-6.28)$. A significant reduction in the risk of adenocarcinoma among patients with the CYP2A13 TT genotype (OR $=0.41,95 \% \mathrm{CI}=0.23$ 0.71 ) was observed in a Chinese population. ${ }^{22}$ On the other hand, a significantly increased risk of adenocarcinoma was seen among subjects with the CYP2A13 CC genotype $(\mathrm{OR}=2.44,95 \% \mathrm{CI}=1.41-$ 4.35). ${ }^{22)}$ Again, our findings coincided with those from Chinese subjects. In contrast, no association was found between this CYP2A13 C3375T polymorphism and the risk of squamous cell carcinoma. ${ }^{22)}$ Cauffiez et al. ${ }^{23)}$ also did not detect the CYP2A13 C3375T polymorphism in a French population although they did find another polymorphism, CYP2A13 C301T, that produced an elevated risk of small cell lung cancer in subjects with the $C T$ genotype $(\mathrm{OR}=9.9,95 \% \mathrm{CI}=1.9-52.2){ }^{23)}$ However, the TT genotype of the CYP2A13 C301T polymorphism was not detected in this French population. Speculation that an adenocarcinoma risk may be linked to the CYP2A13 C3375T polymorphism is biologically plausible for a variety of reasons. The amino acid sequence of CYP2A13 shares a $95.4 \%$ identity with that of CYP2A6. ${ }^{8)}$ Although the latter may play an important role in the activation of TSNAs, its expression in the lung, if any, appears to be relatively low. CYP2A13 has been found to be expressed predominantly in the human lung. ${ }^{18)}$ This enzyme is highly involved in the activation of NNK and some other carcinogens, with a catalytic efficiency much greater than that of CYP2A6. ${ }^{18)}$

As for adenocarcinoma, smokers with the $C C$ genotype of the CYP2A13 C3375T polymorphism showed a significantly higher risk $(\mathrm{OR}=4.88,95 \%$ $\mathrm{CI}=1.35-26.53)$ than non-smokers with at least one copy of the CYP2A13 $T$ allele. Wang et al. ${ }^{22)}$ reported that the risk of adenocarcinoma for the $C C$ genotype of the CYP2A13 C3375T polymorphism among smokers $(\mathrm{OR}=2.94,95 \% \mathrm{CI}=1.45-5.88)$ was higher than that among non-smokers $(\mathrm{OR}=1.67$, $95 \% \mathrm{CI}=0.99-2.86$ ). Furthermore, they indicated that the effect of the $C C$ genotype was evident at low dose of smoking. Genetic susceptibility may be more important even among infrequent smokers. ${ }^{44)}$
From a metabolic point of view, this might be explained by the fact that at high levels the relevant enzyme is saturated irrespective of the genotype, while this does not occur at low levels.

In conclusion, our results do not support a major role for the CYP2A6 gene deletion-type polymorphism as a risk factor for lung adenocarcinoma in our Japanese population. Although the functional C3375T polymorphism in the CYP2A13 gene may be associated with adenocarcinoma, our current limited sample size makes it difficult to establish. Furthermore, the etiology of lung cancer cannot be explained by allelic variability at a single locus. The associations between other functional $C Y P 2 A 13$ polymorphisms and lung cancer risk will require further studies. Therefore, it is likely that the defining feature of future epidemiologic studies will be the simultaneous analysis of large samples of cases and controls. ${ }^{45,46)}$ Advances in identification of new variants and in high-throughput genotyping techniques will facilitate analysis of multiple polymorphisms within the genes with the same pathway. ${ }^{47)}$ The major burden of lung cancer in the population probably results from complex interaction between many genetic and environmental factors over time. The effects of polymorphisms are best represented by their haplotypes. In future association studies on lung cancer, haplotype-based methods will facilitate the evaluation of haplotypic effects, either for selected polymorphisms physically close to each other or for multiple genes within the same drug-metabolism pathway.

Acknowledgements This study was funded in part by a Grant-in-Aid for Scientific Research (C) (14570300) from the Ministry of Education, Culture, Sports, Science and Technology of Japan.

\section{REFERENCES}

1) Coleman, M. P., Esteve, J., Damiecki, P., Arslan, A. and Renard, H. (1993) Lung. In Trends in Cancer Incidence and Mortality, IARC Scientific Publications, No. 121, IARC, Lyon, pp. 311-342.

2) Law, M. R. (1990) Genetic predisposition to lung cancer. Br. J. Cancer, 61, 195-206.

3) Nakachi, K., Imai, K., Hayashi, S. and Kawajiri, K. (1993) Polymorphisms of the CYP1A1 and glutathione S-transferase genes associated with susceptibility to lung cancer in relation to cigarette dose in 
a Japanese population. Cancer Res., 53, 2994-2999.

4) Kiyohara, C. (2000) Genetic polymorphism of enzymes involved in xenobiotic metabolism and the risk of colorectal cancer. J. Epidemiol., 10, 349-360.

5) Smith, T. J., Guo, Z., Gonzalez, F. J., Guengerich, F. P., Stoner, G. D. and Yang, C. S. (1992) Metabolism of 4-(methylnitrosamino)-1-(3-pyridyl)-1butanone in human lung and liver microsomes and cytochromes P-450 expressed in hepatoma cells. Cancer Res., 52, 1757-1763.

6) Staretz, M. E., Murphy, S. E., Patten, C. J., Nunes, M. G., Koehl, W., Amin, S., Koenig, L. A., Guengerich, F. P. and Hecht, S. S. (1997) Comparative metabolism of the tobacco-related carcinogens benzo[a]pyrene, 4-(methylnitrosamino)-1-(3-pyridyl)1-butanone, 4-(methylnitrosamino)-1-(3-pyridyl)-1butanol, and $N^{\prime}$-nitrosonornicotine in human hepatic microsomes. Drug Metab. Dispos., 25, 154-162.

7) Yoshimasu, K. and Kiyohara, C. (2003) Genetic influences on smoking behavior and nicotine dependence: a review. J. Epidemiol., 13, 183-192.

8) Fernandez-Salguero, P., Hoffman, S. M., Cholerton, S., Mohrenweiser, H., Raunio, H., Rautio, A., Pelkonen, O., Huang, J. D., Evans, W. E., Idle, J. R. and Gonzalez, F. J. (1995) A genetic polymorphism in coumarin 7-hydroxylation: sequence of the human CYP2A genes and identification of variant CYP2A6 alleles. Am. J. Hum. Genet., 57, 651-660.

9) Hadidi, H., Zahlsen, K., Idle, J. R. and Cholerton, S. (1997) A single amino acid substitution (Leu160His) in cytochrome P450 CYP2A6 causes switching from 7-hydroxylation to 3-hydroxylation of coumarin. Food Chem. Toxicol., 35, 903-907.

10) Rautio, A., Gullsten, H. and Pelkonen, O. (1998) Expression and function of CYP2A genes in humans. Exp. Toxicol. Pathol., 50, 133-134.

11) Oscarson, M., McLellan, R. A., Gullsten, H., Agundez, J. A., Benitez, J., Rautio, A., Raunio, H., Pelkonen, O. and Ingelman-Sundberg, M. (1999) Identification and characterisation of novel polymorphisms in the CYP2A locus: implications for nicotine metabolism. FEBS Lett., 460, 321-327.

12) London, S. J., Idle, J. R., Daly, A. K. and Coetzee, G. A. (1999) Genetic variation of CYP2A6, smoking, and risk of cancer. Lancet, 353, 898-899.

13) Kamataki, T., Nunoya, K., Sakai, Y., Kushida, H. and Fujita, K. (1999) Genetic polymorphism of CYP2A6 in relation to cancer. Mutat. Res., 428, 125130.

14) Miyamoto, M., Umetsu, Y., Dosaka-Akita, H., Sawamura, Y., Yokota, J., Kunitoh, H., Nemoto, N., Sato, K., Ariyoshi, N. and Kamataki, T. (1999) CYP2A6 gene deletion reduces susceptibility to lung cancer. Biochem. Biophys. Res. Commun., 261,
$658-660$.

15) Ariyoshi, N., Miyamoto, M., Umetsu, Y., Kunitoh, H., Dosaka-Akita, H., Sawamura, Y., Yokota, J., Nemoto, N., Sato, K. and Kamataki, T. (2002) Genetic polymorphism of CYP2A6 gene and tobaccoinduced lung cancer risk in male smokers. Cancer Epidemiol. Biomarkers Prev., 11, 890-894.

16) Fujieda, M., Yamazaki, H., Saito, T., Kiyotani, K., Gyamfi, M. A., Sakurai, M., Dosaka-Akita, H., Sawamura, Y., Yokota, J., Kunitoh, H. and Kamataki, T. (2004) Evaluation of CYP2A6 genetic polymorphisms as determinants of smoking behavior and tobacco-related lung cancer risk in male Japanese smokers. Carcinogenesis, 25, 2451-2458.

17) Tan, W., Chen, G. F., Xing, D. Y., Song, C. Y., Kadlubar, F. F. and Lin, D. X. (2001) Frequency of CYP2A6 gene deletion and its relation to risk of lung and esophageal cancer in the Chinese population. Int. J. Cancer, 95, 96-101.

18) Su, T., Bao, Z., Zhang, Q. Y., Smith, T. J., Hong, J. Y. and Ding, X. (2000) Human cytochrome P450 CYP2A13: predominant expression in the respiratory tract and its high efficiency metabolic activation of a tobacco-specific carcinogen, 4(methylnitrosamino)-1-(3-pyridyl)-1-butanone. Cancer Res., 60, 5074-5079.

19) Zhang, X., Su, T., Zhang, Q. Y., Gu, J., Caggana, M., Li, H. and Ding, X. (2002) Genetic polymorphisms of the human CYP2A13 gene: identification of single-nucleotide polymorphisms and functional characterization of an Arg257Cys variant. $J$. Pharmacol. Exp. Ther., 302, 416-423.

20) Zhang, X., Chen, Y., Liu, Y., Ren, X., Zhang, Q. Y., Caggana, M. and Ding, X. (2003) Single nucleotide polymorphisms of the human cyp2a13 gene: evidence for a null allele. Drug Metab Dispos., 31, 1081-1085.

21) Fujieda, M., Yamazaki, H., Kiyotani, K., Muroi, A., Kunitoh, H., Dosaka-Akita, H., Sawamura, Y. and Kamataki, T. (2003) Eighteen novel polymorphisms of the CYP2A13 gene in Japanese. Drug Metab. Pharmacokinet., 18, 86-90.

22) Wang, H., Tan, W., Hao, B., Miao, X., Zhou, G., He, F. and Lin, D. (2003) Substantial reduction in risk of lung adenocarcinoma associated with genetic polymorphism in CYP2A13, the most active cytochrome $\mathrm{P} 450$ for the metabolic activation of tobaccospecific carcinogen NNK. Cancer Res., 63, 80578061.

23) Cauffiez, C., Lo-Guidice, J. M., Quaranta, S., Allorge, D., Chevalier, D., Cenee, S., Hamdan, R., Lhermitte, M., Lafitte, J. J., Libersa, C., Colombel, J. F., Stucker, I. and Broly, F. (2004) Genetic polymorphism of the human cytochrome CYP2A13 in a 
French population: implication in lung cancer susceptibility. Biochem. Biophys. Res. Commun., 317, 662-629.

24) Kiyohara, C., Nakanishi, Y., Inutsuka, S., Takayama, K., Hara, N., Motohiro, A., Tanaka, K., Kono, S. and Hirohata, T. (1998) The relationship between CYP1A1 aryl hydrocarbon hydroxylase activity and lung cancer in a Japanese population. Pharmacogenetics, 8, 315-323.

25) Ariyoshi, N., Sekine, H., Saito, K. and Kamataki, T. (2002) Characterization of a genotype previously designated as CYP2A6 D-type: CYP2A6*4B, another entire gene deletion allele of the CYP2A6 gene in Japanese. Pharmacogenetics, 12, 501-504.

26) Nunoya, K., Yokoi, T., Takahashi, Y., Kimura, K., Kinoshita, M. and Kamataki, T. (1999) Homologous unequal cross-over within the human CYP2A gene cluster as a mechanism for the deletion of the entire CYP2A6 gene associated with the poor metabolizer phenotype. J. Biochem. (Tokyo), 126, 402-407.

27) Nunoya, K., Yokoi, T., Kimura, K., Kainuma, T., Satoh, K., Kinoshita, M. and Kamataki, T. (1999) A new CYP2A6 gene deletion responsible for the in vivo polymorphic metabolism of (+)-cis-3,5-dimethyl-2-(3-pyridyl)thiazolidin-4-one hydrochloride in humans. J. Pharmacol. Exp. Ther., 289, 437-442.

28) Levi, F., Franceschi, S., La Vecchia, C., Randimbison, L. and Te, V. C. (1997) Lung carcinoma trends by histologic type in Vaud and Neuchatel, Switzerland, 1974-1994. Cancer, 79, 906-914.

29) Wynder, E. L. and Muscat, J. E. (1995) The changing epidemiology of smoking and lung cancer histology. Environ. Health Perspect., 103, 143-148.

30) Patel, A. R. and Obrams, G. I. (1995) Adenocarcinoma of the lung. Cancer Epidemiol. Biomarkers Prev., 4, 175-180.

31) Travis, W. D., Lubin, J., Ries, L. and Devesa, S. (1996) United States lung carcinoma incidence trends: declining for most histologic types among males, increasing among females. Cancer, 77, 2464 2470.

32) Charloux, A., Quoix, E., Wolkove, N., Small, D., Pauli, G. and Kreisman, H. (1997) The increasing incidence of lung adenocarcinoma: reality or artefact? A review of the epidemiology of lung adenocarcinoma. Int. J. Epidemiol., 26, 14-23.

33) Sobue, T., Ajiki, W., Tsukuma, H., Oshima, A., Hanai, A. and Fujimoto, I. (1999) Trends of lung cancer incidence by histologic type: a populationbased study in Osaka, Japan. Jpn. J. Cancer Res., 90, 6-15.

34) U.S. Surgeon General (1981) Health Consequence of smoking - The Changing Cigarette, DHHS
(PHS) 81-50156, Rockville, Md

35) Hecht, S. S., Morse, M. A., Amin, S., Stoner, G. D., Jordan, K. G., Choi, C. I. and Chung, F. L. (1989) Rapid single-dose model for lung tumor induction in $\mathrm{A} / \mathrm{J}$ mice by 4-(methylnitrosamino)-1-(3-pyridyl)1-butanone and the effect of diet. Carcinogenesis, 10, 1901-1904.

36) Hoffmann, D., Rivenson, A., Murphy, S. E., Chung, F.-L., Amin, S. and Hecht, S. S. (1993) Cigarette smoking and adenocarcinoma of the lung: the relevance of nicotine-derived N-nitrosamines. J. Smoking Rel. Disord., 4, 165-190.

37) Hoffmann, D., Brunnemann, K. D., Prokopczyk, B. and Djordjevic, M. V. (1994) Tobacco-specific Nnitrosamines and Areca-derived N-nitrosamines: chemistry, biochemistry, carcinogenicity, and relevance to humans. J. Toxicol. Environ. Health, 41, $1-52$.

38) IARC Monographs of the Evaluation of the Carcinogenic Risk of Chemicals to Humans (2002) Tobacco Smoke and Involuntary Smoking, IARC Scientifc Publication no. 83, IARC, Lyon.

39) Stock, S. L. (1980) Risks the passive smoker runs. Lancet, 2, 1082.

40) Ariyoshi, N., Takahashi, Y., Miyamoto, M., Umetsu, Y., Daigo, S., Tateishi, T., Kobayashi, S., Mizorogi, Y., Loriot, M. A., Stucker, I., Beaune, P., Kinoshita, M. and Kamataki, T. (2000) Structural characterization of a new variant of the CYP2A6 gene (CYP2A6*1B) apparently diagnosed as heterozygotes of CYP2A6*1A and CYP2A6*4C. Pharmacogenetics, 10, 687-693.

41) Oscarson, M., Gullsten, H., Rautio, A., Bernal, M. L., Sinues, B., Dahl, M. L., Stengard, J. H., Pelkonen, O., Raunio, H. and Ingelman-Sundberg, M. (1998) Genotyping of human cytochrome P450 2A6 (CYP2A6), a nicotine C-oxidase. FEBS Lett., 438, 201-205.

42) Oscarson, M., McLellan, R. A., Gullsten, H., Yue, Q. Y., Lang, M. A., Bernal, M. L., Sinues, B., Hirvonen, A., Raunio, H., Pelkonen, O. and Ingelman-Sundberg, M. (1999) Characterisation and PCR-based detection of a CYP2A6 gene deletion found at a high frequency in a Chinese population. FEBS Lett., 448, 105-110.

43) Raunio, H., Rautio, A., Gullsten, H. and Pelkonen, O. (2004) Polymorphisms of CYP2A6 and its practical consequences. Br. J. Clin. Pharmacol., 52, 357363.

44) Vineis, P. and Martone, T. (1995) Genetic-environmental interactions and low-level exposure to carcinogens. Epidemiology, 6, 455-457.

45) Caporaso, N. E. (2002) Why have we failed to find the low penetrance genetic constituents of common 
cancers? Cancer Epidemiol. Biomarkers Prev., 11, 1544-1549.

46) Brennan, P. (2002) Gene-environment interaction and aetiology of cancer: what does it mean and how can we measure it? Carcinogenesis, 23, 381-387.
47) Goode, E. L., Ulrich, C. M. and Potter, J. D. (2002) Polymorphisms in DNA repair genes and associations with cancer risk. Cancer Epidemiol. Biomarkers Prev., 11, 1513-1530. 